\title{
Effects of Plastic Pre-Straining Level on the Creep Deformation, Crack Initiation and Growth Behaviour of 316H Stainless Steel
}

\author{
Ali Mehmanparast ${ }^{\mathrm{a} *}$, Catrin M. Davies ${ }^{\mathrm{b}}$, David W. Dean ${ }^{\mathrm{c}}$, Kamran Nikbin ${ }^{\mathrm{b}}$ \\ ${ }^{a}$ Offshore Renewable Energy Centre, Cranfield University, Cranfield, Bedfordshire MK43 OAL, UK \\ ${ }^{b}$ Department of Mechanical Engineering, Imperial College London, South Kensington Campus, London, SW7 2AZ, UK \\ ${ }^{c}$ EDF Energy, Barnett Way, Barnwood, Gloucester, GLA 3RS, UK \\ *Corresponding author email address: a.mehmanparast@cranfield.ac.uk
}

\begin{abstract}
The effects of the material pre-straining level, in the form of plastic pre-compression at room temperature, on the tensile, creep deformation, creep crack initiation and growth behaviour of $316 \mathrm{H}$ stainless steel have been examined at $550{ }^{\circ} \mathrm{C}$. Experiments have been performed on the $4 \%, 8 \%$ and $12 \%$ pre-compressed specimens and the results are compared with existing data on the pre-compressed material to investigate the change in mechanical response, creep failure, creep crack initiation and growth behaviour of $316 \mathrm{H}$ over a range of plastic pre-straining levels. Comparisons are also made to short term and long term test data on the as-received material. It has been found that creep ductility and rupture times decreased with an increase in pre-strain levels considered. The test results obtained from different material states are discussed in terms of the influence of material pre-straining level on the microstructural deformation, mechanical response, creep deformation and crack growth behaviour of the material.
\end{abstract}

Keywords: Pre-straining level, Pre-compression, CCG, Creep ductility, Long term creep, 316H

\section{Nomenclature}

$a$

$a_{0}$

$\dot{a}($ or $d a / d t)$

$\Delta a$

A

$A_{A}$

$B$

$B_{n}$

$B_{r}$

$C^{*}$

$D$

E

$E^{\prime}$
Crack length

Initial crack length

Creep crack growth rate

Increment of crack growth

Creep stress coefficient in minimum creep strain law

Creep stress coefficient in average creep strain law

Specimen thickness

Net specimen thickness between the side grooves

Coefficient of rupture law

Steady state creep fracture mechanics parameter

Constant coefficient in creep crack growth correlation with $C^{*}$

Elastic (Young's) modulus

Effective Young's modulus 
$K$

$n$

$n_{A}$

$P$

$t_{0.2}$

$t_{0.5}$

$t_{f}$

$t_{i}$

$t_{\text {red }}^{\text {eng }}$

$t_{r}$

$t_{T}$

W

$\eta$

$\varepsilon_{f}$

$\dot{\varepsilon}_{S}$

$\dot{\varepsilon}_{A}$

$v_{r}$

$\phi$

$\Delta$

$\Delta_{c}$

$\Delta_{e}$

$\dot{\Delta}$

$\dot{\Delta}^{c}$

$\dot{\Delta}^{i}$

$\dot{\Delta}_{e}^{i}$

$\dot{\Delta}^{T}$

$\sigma$

$\sigma_{0.2}$

$\sigma_{\text {ref }}$

$\mathrm{AR}$

CCG

CCI

LLD

PC
Stress intensity factor

Creep stress exponent in minimum creep strain law

Creep stress exponent in average creep strain law

Applied load

Time for $0.2 \mathrm{~mm}$ crack extension

Time for $0.5 \mathrm{~mm}$ crack extension

Creep crack growth test duration

Initiation time

Engineering redistribution time

Time to rupture in a uniaxial creep test

Transition time from small scale creep to widespread creep conditions

Specimen width

Geometry function in $C^{*}$ relation

Uniaxial creep strain at failure (creep ductility)

Steady state creep strain rate

Average creep strain rate

Creep rupture stress exponent

Exponent in correlation of creep crack growth rate with $C^{*}$

Load line displacement

Creep load line displacement

Elastic load line displacement

Load line displacement rate

Component of displacement rate directly associated with the accumulation of creep strains

Component of displacement rate directly associated with instantaneous (elastic and plastic) strains

Component of displacement rate directly associated with instantaneous elastic strains

Total load line displacement rate

Stress

$0.2 \%$ proof stress

Reference stress

As-received material

Creep crack growth

Creep crack initiation

Load line displacement

Pre-compressed material 
Stainless steel

UTS

Ultimate tensile strength

\section{Introduction}

The influence of plastic pre-strain on the deformation and creep behaviour of $316 \mathrm{H}$ stainless steel has been the focus of many studies in recent years (see [1-5]). Understanding the effects of plastic pre-strain on the behaviour of structural components is essential for structural integrity assessments as some degree of plastic strain is introduced into components by most manufacturing processes including forging and welding (see e.g. $[1,2])$.

As discussed in [1] power plant components are often manufactured by forming (plastic pre-straining) of stainless steel tubes which are subsequently welded into the required shapes. The extent of prior plastic strains introduced into the material can significantly change the mechanical properties and consequently affect the residual stresses after welding [1]. The material pre-straining effects on subsequent mechanical and fracture behaviour of engineering alloys have previously been investigated by other researchers [3, 6-11]. A study of the creep behaviour in polycrystalline copper samples pre-strained to different amounts at room temperature and high temperature in [6] has shown that the creep ductility in this material had reduced due to prestraining; however, the creep strain rate and rupture life increased or decreased depending on the testing conditions. A similar study on Nimonic 80A pre-tensioned to different plastic strain levels of up to $15 \%$ at room temperature has shown that the creep ductility decreases by increasing the material pre-straining amount [7]. It has been shown in [8] that small pre-straining of AISI 304 stainless steel at high temperature improves the creep strength of the material. The creep tests on ex-service 316 material subjected to room temperature pre-straining up to $39 \%$ in [9] showed that by increasing the percentage of pre-strain, the rupture life, minimum creep strain rate and creep ductility reduce significantly. A review of the previous studies on various engineering alloys show that the creep ductility of the examined materials always continuously decreased by increasing the amount of plastic pre-straining at room temperature.

The material examined is this study is Type $316 \mathrm{H}$ stainless steel (SS) which is widely used in the advanced gas cooled reactor (AGR) plant components which often operate at temperatures of around $550{ }^{\circ} \mathrm{C}$. It has been shown in [12] that material pre-strain on Type $316 \mathrm{H}$ may change the average grain size; however, no change in grain size was observed in [13] where the material was uniformly pre-compressed (PC) to $8 \%$ plastic strain at room temperature. Significant work has been done recently to investigate the mechanical and creep deformation and crack growth behaviour of 316H SS material pre-compressed to $8 \%$ plastic strain at room temperature [5]. It has been shown in [5] that material pre-compression to $8 \%$ plastic strain increases the yield stress (thus the hardness) of $316 \mathrm{H} \mathrm{SS}$, reduces the creep ductility and rupture time in uniaxial creep tests, and increases the creep crack growth (CCG) rates by around an order of magnitude when compared to the results obtained from the as-received (AR) material. Preliminary results on both $4 \%$ and $8 \% \mathrm{PC} 316 \mathrm{H}$ at $550{ }^{\circ} \mathrm{C}$ suggest that the creep ductility reduces as the level of plastic strain increases $[5,14,15]$; however, in order to quantify this effect further tests were required at a range of plastic strain levels.

In this work additional tensile, uniaxial creep and CCG tests have been performed on specimens uniformly pre-compressed to $4 \%, 8 \%$ and $12 \%$ plastic strain at room temperature. The new test results from specimens with different extents of pre-strain are compared with the existing data on the PC material to investigate the change in mechanical response, creep failure, creep crack initiation (CCI) and growth behaviour of $316 \mathrm{H}$ over this range of plastic pre-straining levels. 


\section{Material Pre-Straining and Specimen Design}

The material utilised in this study is ex-service Type $316 \mathrm{H}$ stainless steel extracted from a steam header provided by EDF Energy. Blocks of material were uniformly pre-compressed to 4\%, $8 \%$ and $12 \%$ plastic true strain at room temperature and a number of uniaxial round bar specimens or a single compact tension, $\mathrm{C}(\mathrm{T})$, sample were extracted from each pre-strained block. The round bar samples used for tensile and uniaxial creep rupture tests had the same dimensions of $8 \mathrm{~mm}$ diameter and $36 \mathrm{~mm}$ gauge length. All C(T) specimens had the same width of $W=50 \mathrm{~mm}$ and the total thickness of $B=25 \mathrm{~mm}$. The starter crack in $\mathrm{C}(\mathrm{T})$ specimens was introduced by an EDM (Electrical Discharge Machining) pre-crack of notch root radius $0.125 \mathrm{~mm}$. All specimens were extracted from the same header, denoted Header A. Previous tests, to which these results will be compared, have however been extracted from three different headers of similar composition.

\section{Creep Deformation, Crack Initiation and Growth Relations}

\subsection{Uniaxial Creep Deformation and Rupture}

For power law, creeping materials under steady state conditions, the minimum creep strain rate, $\dot{\varepsilon}_{s}$, may be correlated with the equivalent stress, $\sigma$, by the Norton creep law [16] using the relation

$$
\dot{\varepsilon}_{s}=A \sigma^{n}
$$

where $n$ and $A$ are the power law creep stress exponent and coefficient, respectively. Similarly, at a given temperature the rupture time may be described by the power law relationship

$$
t_{r}=B_{r} \sigma^{-v_{r}}
$$

where $B_{r}$ and $v_{r}$ are the rupture life power law stress coefficient and exponent, respectively. In order to account for the deformation in different creep regions, the average creep strain rate, $\dot{\varepsilon}_{A}$, is often employed which is defined as

$$
\dot{\varepsilon}_{A}=\varepsilon_{f} / t_{r}
$$

where $\varepsilon_{f}$ is the creep ductility and $t_{r}$ is the rupture time. Similar to Eqn (1), the stress dependency of the average creep strain rate may be described by the power law relationship

$$
\dot{\varepsilon}_{A}=A_{A} \sigma^{n_{A}}
$$

where $A_{A}$ and $n_{A}$ are the power law stress coefficient and exponent, respectively. Combining Eqns (2)-(4), the stress dependency of the creep ductility (i.e. creep strain at failure) for a given temperature can be expressed as

$$
\varepsilon_{f}=A_{A} B_{r} \sigma^{n_{A}-v_{r}}
$$

It can be deduced from Eqn (5) that for a given temperature and stress range, the creep ductility is stress independent when $n_{A}=v_{r}$.

\subsection{Creep Crack Growth Relations}

When a steady state of creep deformation and damage has developed ahead of a crack tip, the CCG rate, $\dot{a}$ (or $d a / d t$ ), may be described by the steady state creep fracture mechanics parameter $C^{*}$ using

$$
\dot{a}=D C^{* \phi}
$$


where $D$ and $\phi$ are material constants [17]. As explained in [17] under steady state creep conditions $\dot{a} v s . C^{*}$ data appear as a straight line on log-log axes. However, before the steady state conditions are achieved, data points will appear as a 'tail' on the $\dot{a} v s . C^{*}$ plot.

The $C^{*}$ fracture mechanics parameter in CCG tests may be evaluated experimentally using the load line displacement (LLD) rate measurements, $\dot{\Delta}$, by the relation [18]

$$
C^{*}=\frac{P \dot{\Delta}}{B_{n}(W-a)} H \eta
$$

where $P$ is the applied load, $B_{n}$ is the net specimen thickness between the side grooves, $a$ is the instantaneous crack length and $W$ is the specimen width. $H$ and $\eta$ in Eqn (7) are geometry dependent constants. For a standard C(T) specimen with $0.45 \leq a / W \leq 0.7, H=n /(n+1)$ and $\eta=2.2$ [18]. The solutions of $\eta$ factor for $\mathrm{C}(\mathrm{T})$ specimens with $0.35 \leq a / W<0.45$ are provided using finite element (FE) simulations and given in [5].

\subsection{Load Line Displacement Measurements}

The total LLD rate, $\dot{\Delta}^{T}$, in a CCG test can be partitioned into an instantaneous part, $\dot{\Delta}^{i}$, and a time-dependent creep part, $\dot{\Delta}^{c}$, such that

$$
\dot{\Delta}^{T}=\dot{\Delta}^{c}+\dot{\Delta}^{i}
$$

The instantaneous displacement rate, $\dot{\Delta}^{i}$, can be further divided into an elastic and a plastic part, with the elastic part of the instantaneous LLD rate, $\dot{\Delta}_{e}^{i}$, calculated by

$$
\dot{\Delta}_{e}^{i}=\frac{\dot{a} B_{n}}{P}\left[\frac{2 K^{2}}{E^{\prime}}\right]
$$

where $K$ is the stress intensity factor and $E^{\prime}$ is the effective elastic modulus $\left(E /\left(1-v^{2}\right)\right.$ for plane strain and $E$ for plane stress conditions). Relations for approximation of the instantaneous plastic displacement rate are given in [19]. However, in the CCG data analysis of the pre-strained 316H SS the contribution of plasticity in the LLD measurements may be considered negligible due to the large yield stress in materials pre-compressed to different extents of plastic strain [5], thus this term is neglected in LLD calculations. Note that according to the ASTM E1457 standard, the displacement rate used in the evaluation of the $C^{*}$ parameter (see Eqn (7)) is often taken to be the total LLD rate $\dot{\Delta}^{T}[19]$.

\section{4. $C^{*}$ Validity Criteria}

The validity criteria for the use of the $C^{*}$ fracture mechanics parameter in $\mathrm{CCI}$ and growth data analysis are specified in [19]. These are that (i) the transition time, $t_{T}$, from an elastic crack tip field to a $C^{*}$ controlled creep crack tip field must be exceeded, where the transition time can be calculated using [19]

$$
t_{T}=\max \left[\frac{K^{2}}{E^{\prime}(n+1) C^{*}}\right]
$$

(ii) data points obtained prior to a crack extension, $\Delta a$, of $0.2 \mathrm{~mm}$ must be excluded (iii) to exclude the data points with the LLD, $\Delta^{L L D}$, greater than $0.05 \mathrm{~W}$ (iv) the creep LLD rate must constitute at least half of the total LLD rate i.e. $\dot{\Delta}^{c} / \dot{\Delta}^{T} \geq 0.5$. When the latter criterion is satisfied the material is referred to as "creep ductile" and the CCG rate can be described using the $C^{*}$ fracture mechanics parameter.

Additional validity criteria are also proposed in the R5 procedure [20] and in [21] which suggest that the non-dimensional crack velocity, $\lambda$, must be less than 0.5 and the engineering redistribution time, $t_{\text {red }}^{e n g}$, must be 
exceeded in order to use $C^{*}$ as a valid parameter to characterise the CCG behaviour of a material. It has been discussed in [21] that the engineering redistribution time, compared to the transition time estimated using Eqn (10), is a more accurate criterion to check widespread creep conditions in CCG tests on $316 \mathrm{H}$ stainless steel. The $\lambda$ and $t_{r e d}^{\text {eng }}$ for these additional validity criteria can be calculated using

$$
\begin{gathered}
\lambda=\frac{\dot{a}\left(\sigma_{r e f}\right)^{2}}{E C^{*}{ }_{\text {exp }}} \\
\frac{\Delta_{c}\left(t_{\text {red }}^{\text {eng }}\right)}{\Delta_{e}\left(t_{\text {red }}^{\text {eng }}\right)}=0.208
\end{gathered}
$$

where $\sigma_{r e f}$ is the reference stress (the solutions of which are given in [22] for a range of specimen geometries), $\Delta_{c}$ is the creep LLD and $\Delta_{e}$ is the elastic LLD measurement.

\subsection{Creep Crack Initiation Relation}

The CCI time, $t_{i}$, is often referred to the amount of time for creep strain/damage to build up ahead of the crack tip prior to crack extension from a pre-existing defect. The initiation time in CCG tests is conventionally reported for 0.2 or $0.5 \mathrm{~mm}$ of crack extension, $\Delta a$, and denoted as $t_{0.2}$ and $t_{0.5}$, respectively [19]. It has been shown and discussed in [5] that in the CCG tests on PC $316 \mathrm{H}$ material, the calculated engineering redistribution time is close to or shorter than the initiation time. Therefore, assuming that the CCI time in all tests on PC material is greater than the redistribution time, an approximate value of CCI time may be obtained using

$$
t_{i}=\frac{\Delta a}{\dot{a}}=\frac{\Delta a}{D C^{* \phi}}
$$

\section{Pre-compression Effects on Tensile Behaviour}

Tensile tests have been performed on the $\mathrm{AR}, 4 \% \mathrm{PC}, 8 \% \mathrm{PC}$ and $12 \% \mathrm{PC}$ materials at room temperature and $550{ }^{\circ} \mathrm{C}$ and the results are shown in Figure 1(a) and (b), respectively. From here on, all test data obtained from AR, 4\%, $8 \%$ and 12\% PC material are shown in red, purple, blue and green symbols, respectively. The tensile properties obtained from the tests on different material states are summarised in Table 1 . As seen in Figure 1(a), (b) and Table 1, at both room temperature and $550{ }^{\circ} \mathrm{C}$ similar values of the Young's modulus, $E$, and the ultimate tensile strength (UTS) have been found for the AR specimen and the materials precompressed to different extents of plastic strain. As shown in Table 1, the room temperature values of $0.2 \%$ proof stress, $\sigma_{0.2}$, increase with the percentage of pre-compression, though these values fall below that obtained from the AR material. This is thought to be due to a significant contribution of kinematic hardening and early yielding on reverse loading for this material which generally exhibits combined isotropic-kinematic hardening behaviour. Also seen in Table 1, Figure 1(a) and (b), is that the values of $0.5 \%$ proof stress, $\sigma_{0.5}$, at room temperature and also $\sigma_{0.2}$ and $\sigma_{0.5}$ at $550{ }^{\circ} \mathrm{C}$ progressively increase with increasing the percentage of precompression from $0 \%$ (AR material) to $12 \%$ plastic pre-strain, thus generally material hardening increases with the level of pre-compression, as expected. There is a clear reduction in tensile ductility for the $12 \%$ PC sample at both room temperature and $550{ }^{\circ} \mathrm{C}$. Similar tensile ductilities are, however, found for the $4 \% \mathrm{PC}$, $8 \% \mathrm{PC}$ and $\mathrm{AR}$ sample at room temperature. A general reduction in tensile ductility with an increase in the percentage of pre-compression is seen at $550{ }^{\circ} \mathrm{C}$. 


\section{Pre-compression Effects on Creep Deformation and Rupture Behaviour}

Uniaxial creep rupture tests have been performed on six 12\% PC specimens (denoted 12PC) and a 4\% PC sample (denoted 4PC). In addition, nine relatively high stress uniaxial creep tests have been performed on $8 \%$ PC material (denoted 8PC). All tests were performed at $550{ }^{\circ} \mathrm{C}$ and a summary of the loading conditions and test results are given in Table 2. As seen in this table, all the applied stresses on the $12 \%$ PC samples are below the yield stress of this material state at $550{ }^{\circ} \mathrm{C}$, thus zero or negligible plasticity was observed during the loading of these tests. As a result, the calculated true stress, $\sigma_{\text {true }}$, values have been found close to the nominal stresses $\sigma_{\text {nom }}$. The existing uniaxial creep data on the AR and 8\% PC material taken from [5] and also the limited data available on the 4\% PC material taken from [14] are collated, presented next and compared with results from the tests performed as part of this study .

\subsection{The Influence of Pre-compression Level on Creep Rupture}

The creep curves for the $\mathrm{AR}, 4 \% \mathrm{PC}, 8 \% \mathrm{PC}$ and $12 \% \mathrm{PC}$ materials tested under $300 \mathrm{MPa}$ at $550{ }^{\circ} \mathrm{C}$ are shown and compared in Figure 2. It can be seen in this figure that for a given applied stress, a continuous reduction in the rupture time and creep ductility can be observed by increasing the extent of material prestraining. Note that significant plastic loading strains were developed at $300 \mathrm{MPa}$ for the AR, 4\% PC and $8 \%$ PC materials at $550{ }^{\circ} \mathrm{C}$ (see Table 1). However, due to the larger yield stress in $12 \%$ PC material, a linear elastic response was observed during the load up of this specimen. In order to examine the effect of precompression on the creep deformation and rupture behaviour of the material at a given stress and temperature, the creep ductility and rupture time data obtained from the tests performed on AR, 4\% PC, $8 \%$ PC and $12 \%$ $\mathrm{PC}$ specimens at $300 \mathrm{MPa}$ and $550{ }^{\circ} \mathrm{C}$ are plotted in Figure 3. As seen in this figure, for the given stress and temperature, a gradual decrease in both rupture time and creep failure strain can be observed by increasing the pre-compression level. These trends are consistent with those reported for pre-tensioned 316 in [9] where a creep ductility plateau of around $1 \%$ was observed for specimens pre-strained to percentages beyond approximately $20 \%$.

The rupture time against applied stress is plotted in Figure 4 for the AR, 4\% PC, $8 \%$ PC and 12\% PC materials. A power law fit has been made treating all data for a given level of PC as a single data set. The power law constants determined are given in Table 3. Note that the data points for $4 \%$ PC generally fall between the AR and 8\% PC data; however, there are insufficient data points to fit a trend line to the $4 \% \mathrm{PC}$ data. As seen in Figure 4, a gradual reduction in rupture time for a given stress can be seen with an increase in the pre-compression level. Figure 4 and Table 3 show that for a given value of applied stress, the rupture time is on average around 2.5 and six times lower in the $8 \% \mathrm{PC}$ and $12 \% \mathrm{PC}$ materials, respectively, compared to the AR material.

\subsection{The Influence of Pre-compression Level on the Creep Strain Rate}

The average and minimum creep strain rate data for the AR, $4 \%$ PC, $8 \%$ PC and $12 \%$ PC materials are plotted against the nominal stress in Figure 5(a) and (b), respectively, and the power law constants are given in Table 3. As seen in Figure 5 similar average and minimum creep strain rate trends can be generally observed in the AR and PC materials. This implies that for the range of stresses examined, the average and minimum creep strain rate trends are relatively insensitive to the material pre-straining level. 


\subsection{The Influence of Pre-compression Levels on Creep Ductility}

In Figure 6 the creep ductility has been plotted against the applied stress normalised by the $0.2 \%$ proof stress of the material (taken from Table 1), which signifies the extent of plastic strain generated in the sample on loading [23]. Also included in this figure are the AR experimental data points from an existing large data set, and the estimated creep ductility trends, over a wide range of stresses, for the AR material at $550{ }^{\circ} \mathrm{C}$ taken from [23]. As explained in [23], three regions have been identified - the upper shelf and lower shelf creep ductility regions observed at high and low stress regions, respectively, where the creep ductility is constant, which are joined by a stress dependent transition region. It can be observed in Figure 6 that the PC creep ductility data points generally follow the creep ductility trends estimated from the AR material. Note that the stress dependency of the total inelastic strain at failure (i.e. the sum of the PC strain, plastic strain on loading and creep strain at failure) was examined; however, no clear trends were generally found. The creep strain at failure and plastic loading strains were negligible compared to the PC strain in the $12 \%$ PC samples thus the inelastic strain was effectively constant and stress independent. An increase in inelastic strain with stress was seen for the $8 \%$ PC material, but this was due to the increase in creep ductility with stress, as shown in Figure 6.

\section{Pre-compression Effects on Creep Crack Initiation and Growth Behaviour}

Creep crack growth tests were performed on standard $\mathrm{C}(\mathrm{T})$ specimens with the initial normalised crack length of $a_{0} / W=0.5$ made of the $4 \%, 8 \%$ and $12 \%$ pre-compressed materials. For reasons explained in [5] tests were also performed on $8 \% \mathrm{C}(\mathrm{T})$ specimens with $a_{0} / W=0.35$, which have been demonstrated to be valid through the use of appropriate geometric functions. Note that the geometric solutions given in ASTM E1457 [19] are valid for $0.45 \leq a / W \leq 0.7$. A summary of specimen dimensions, loading conditions and the CCG test results is shown in Table 4 in which $W$ is the specimen width, $B$ is the thickness, $B_{n}$ is the net thickness between the side grooves, $a_{0}$ is the initial crack length, $K\left(a_{0}\right)$ is the stress intensity factor at initial loading, $\Delta a$ is the creep crack extension and $t_{f}$ is the test duration. As seen in Table 4, all specimens had the same width and total thickness; however, the values of net thickness were different in various specimens.

The reference stress normalised by $0.2 \%$ proof stress of the material indicated the level of plasticity in the sample [17]. A ratio of much less than unity, calculated using the equations given in [24] for a range of specimen geometries, indicates limited plasticity whereas the ratio of much larger than unity implies widespread plasticity in a fracture specimen. The normalised reference stress value on loading has been reported in Table 4 for each of the tests examined. As seen in this table, the $\sigma_{r e f} / \sigma_{0.2}$ ratio was much less than unity on loading and throughout the test for all CCG tests performed on PC materials, indicating that the plasticity effects on the CCG behaviour of these PC specimens were negligible. Not shown here for brevity, linear responses were generally observed during the loading process in CCG tests on PC specimens, which also confirms that the plasticity effects during load up were limited.

\subsection{Crack Growth and Load Line Displacement Variation}

The change in the LLD measurements subsequent to load up normalised by the specimen width, $\Delta / W$, and the CCG, $\Delta a$, behaviour of the PC specimens are plotted against time normalised by test duration, $t_{f}$, and the results are shown in Figure 7(a) and (b), respectively. Rapid increase in the LLD rate and crack extensions have been measured towards the end of the majority of the tests examined. Note that the creep crack extension and LLD trends during the tests are dependent on the point at which the test was stopped, prior to final failure of the specimen. For this reason, the CCG and LLD rates in the relatively long term (i.e. low load) tests on 
4PC-A1 and 4PC-A2 specimens, shown in Figure 7(b), are not as large as the other tests examined on PC materials. Further seen in Figure 7(a) and (b) is that within the experimental data scatter similar LLD and CCG trends can be observed in 8PC-A7, 8PC-A8, 8PC-A9 and 8PC-A10 specimens which were precompressed to the same percentage of plastic strain $(8 \%)$, had nominally identical dimensions and were subjected to the same loading conditions (see Table 4).

\section{2. $C^{*}$ Validity Criteria}

The validity criteria for the use of the $C^{*}$ creep fracture mechanics parameter specified in Section 3.4 are examined in Figure 8. In this figure the valid data points are shown in coloured symbols whereas the invalid data points are shaded in grey. It can be seen in Figure 8 that the $\dot{\Delta}^{c} / \dot{\Delta}^{T}$ ratio in $4 \%$ pre-compressed specimens, 4PC-A1 and 4PC-A2, is greater than 0.5 for the majority of test duration, though $\dot{\Delta}^{c} / \dot{\Delta}^{T}$ of larger than 0.5 is only observed for almost $50 \%$ of the test duration in the $12 \mathrm{PC}-\mathrm{A} 1$ and $12 \mathrm{PC}-\mathrm{A} 2$ specimens. This indicates that the elastic contribution to the LLD rate in the material with $12 \%$ plastic strain is more severe than the 4\% PC material. Also seen in Figure 8 is that, for a given value of the normalised time, the $\dot{\Delta}^{c} / \dot{\Delta}^{T}$ trend for the $8 \%$ PC specimens falls upon or in between those seen in $4 \%$ and $12 \%$ PC materials. These $\dot{\Delta}^{c} / \dot{\Delta}^{T}$ data are generally less than that for the AR $316 \mathrm{H}$ material at $550{ }^{\circ} \mathrm{C}$, which is typically close to unity [25]. This trend indicates that the elastic contribution in LLD rates generally increases with the percentage pre-compression in the material.

\subsection{Correlation of the CCG Data with the $C^{*}$ Fracture Mechanics Parameter}

The CCG rate data from the PC specimens are correlated with the $C^{*}$ parameter as shown in Figure 9. Note that the CCG data previously presented in [15] have been re-analyzed here with updated creep strain rate data and additional $C^{*}$ validity criteria (see Section 3.4). Although only the data points considered valid according to the criteria specified in Section 3.4 have been included in Figure 9, some tails are still apparent in the CCG data. As seen in Figure 9 the CCG results from relatively long term tests on 4\% PC specimens, 4PC-A1 and 4PC-A2, fall in the low $C^{*}$ region; however, the CCG trend from these tests is consistent with the shorter term test on 4PC-B3 specimen. Also seen in Figure 9 is that for the tests examined, the CCG trends from 4\% PC and 12\% PC materials fall upon the lower and upper bound fits to the $8 \%$ CCG data band, respectively. The $8 \%$ PC (8PC-A5) and 12\% PC (12PC-A1 and 12PC-A2) specimens with nominally identical dimensions and tested under similar loading conditions show that, for a given value of $C^{*}$, the CCG rate in $12 \% \mathrm{PC}$ material is around twice as high as that observed in the $8 \% \mathrm{PC}$ material.

\subsection{Comparison of the CCG Trends with the Existing Data on the As-received Material}

All the available CCG data from the PC specimen tests are compared in Figure 10. Also included in Figure 10 are the mean (solid line) and upper bound (UB) / lower bound (LB) (dashed lines) trend lines fitted to the short term (shown in red) and long term (shown in pink) AR data [21]. The mean and UB/LB fits to the 8\% PC data set are also included in this figure. The corresponding power law constants $D$ and $\phi$ (see Eqn (6)) are given in Table 5. Note that due to the extensive tail regions observed in the CCG data on 4\% PC and 12\% PC data, the power law exponents found for these data sets were beyond unity, thus invalid according to the CCG prediction models [26]; however, the values given in Table 5 have been found by ignoring the tail regions as recommended in [17]. Due to the limited data available for the $4 \%$ PC and $12 \%$ PC materials, the UB/LB factors are not quantified for these two data sets.

It can be seen in Figure 10 that ignoring the tail regions, the CCG data on 4\% PC material follow the trend of the mean fit to the $8 \%$ PC material and fall upon the UB fit to the long term tests on the AR material. Also 
seen in this figure is that the $8 \% \mathrm{PC}$ data sets are effectively coincident and, for a given value of $C^{*}$, the CCG rates are on average around seven times higher than those from short term AR data. Finally seen in Figure 10 is that the CCG data for $12 \%$ PC material fall upon or are close to the UB fit to the $8 \%$ PC data and the CCG rate for this material is on average around three times higher than the mean fit to the $8 \% \mathrm{PC}$ material, for a given value of $C^{*}$.

\subsection{Creep Cracking Mode in Pre-compressed Specimens}

As an example, the creep cracking mode at the mid thickness of a 4\% $\mathrm{PC} \mathrm{C}(\mathrm{T})$ specimen (4PC-A2) is shown in Figure 11. It can be observed that the cracking mode in this test was, as termed in [21], 'brittle inter-granular', i.e. where the CCI and growth occurs with no clear evidence of grain deformation. This observation is consistent with the cracking mode seen in the 8\% PC CCG test demonstrated in [5] and also the long term tests on the AR material shown in [21]. Multiple, discontinuous inter-granular micro-cracks, orientated normal to the loading axis, are observed in Figure 11. However, due to the three-dimensional nature of the CCG process, the crack is thought to have been continuous along other planes through the thickness of the specimen, as shown for an $8 \%$ PC C(T) sample in [5].

\subsection{Comparison of the Creep Crack Initiation Trends in the As-received and Pre-compressed Materials}

The validity criteria specified in Section 3.4 for correlating the initiation time with the $C^{*}$ parameter were applied to the data and it was considered that $C^{*}$ is an appropriate parameter to correlate with the CCI times corresponding to $0.2 \mathrm{~mm}\left(t_{0.2}\right)$ and $0.5 \mathrm{~mm}\left(t_{0.5}\right)$ crack extension. These correlations are shown in Figure 12(a) for $t_{0.2}$ and Figure 12(b) for $t_{0.5}$. Also included in Figure 12 are the experimental CCI trends calculated by employing the steady state CCG power law constants obtained from the line of best fits to the $8 \%$ PC and short term AR data (see Eqn (13) and Table 5).

Most of the PC data points for all levels of PC shown in Figure 12(a) fall close to the experimental CCI trend line for the $8 \%$ PC material, though a number of $8 \%$ PC points fall closer towards the AR trend line. Similar observations are made in Figure 12(b) for $t_{0.5}$. The scatter in the data may be attributed to a number of factors including crack tip plasticity effects causing crack tip blunting and thus reducing crack tip triaxiality and the general difficulty in measuring small crack extensions. The long term AR CCI data fall between the short-term AR and $8 \%$ PC material trend lines thus the $8 \%$ PC material trend line provides a conservative prediction for the long term CCI behaviour of the AR material.

\section{Discussion}

Work was performed in [9] where 316 material was pre-tensioned to a range of strains up to $39 \%$. It was found that for a given applied load the creep ductility initially reduced with percentage pre-strain, but plateaued to a lower limit of about $1 \%$ creep ductility when the pre-strain attained levels of greater than around $20 \%$. Pre-compression effects are therefore similar to pre-tension for this material as for up to $12 \%$ PC, as shown in Figure 3, the creep ductility reduces with the level of plastic pre-strain. The results in [9] may also corroborate the inferred trends from [23] shown in Figure 6 since the $12 \%$ PC data at $\sigma / \sigma_{0.2}<1$ are around the estimated lower bound limit of $1 \%$ for this material; however, further tests are required to confirm this.

It was shown in Figure 10 that the CCG trends for the 4\%, 8\% and 12\% PC materials are around an order of magnitude higher than that of short term tests on AR material, for a given value of $C^{*}$. As discussed in [5], this is partly due to the loss of crack tip constraint in the short-term AR test which has a relatively low yield 
strength and thus high levels of crack tip plasticity. In addition, PC reduces the creep ductility of the material, hence CCG rates are increased. The CCG rate is also influenced by the creep strain rate properties of the material, but this effect may be considered small compared to the creep ductility and specimen constraint effects.

Observed in Figure 6 and Figure 10 is that the lowest ductilities (for a given applied stress) and the highest CCG rates were observed in the experiments performed on the $12 \%$ PC material. Also seen in Figure 10 is that the CCG tests on 12\% PC material provide CCG rates of around three times higher than the UB fit to the long term data on the AR material, whereas the data from $4 \%$ and $8 \%$ PC specimens fall upon the UB fit to the long term AR data. This suggests that a more conservative prediction of the CCG behaviour in long term tests on AR material may be provided, in much shorter time scales, by performing tests on specimens subjected to relatively large amounts of plastic pre-strain. It must be noted that the majority of the CCG tests presented in this work lasted for around 1000 hours or less. Therefore, longer term tests under relatively lower load levels need to be performed in future work to investigate the test duration effects on the longer term CCG response of the PC material.

Increasing the percentage of pre-compression, to for instance $12 \%$ plastic pre-strain in an ex-service material, may lead to an increase in intergranular cavity density and not necessarily cavity growth rate [7]. In other words when the percentage pre-compression increases in a given polycrystalline material (and hence the yield stress increases) the creep deformation within the grains becomes progressively less important and the creep rupture behaviour strongly depends on the intergranular failure due to the increased number of cavities along the grain boundaries [27]. The increase in intergranular cavity density with an increase in amount of plastic pre-compression leads to lower uniaxial creep ductilities and thus higher CCG rates as observed in the experimental data for the $12 \%$ PC material.

\section{Conclusions}

The effects of percentage plastic pre-strain on the tensile, uniaxial creep deformation, CCI and growth behaviour of $316 \mathrm{H}$ stainless steel at $550{ }^{\circ} \mathrm{C}$ have been examined. The yield stress was found to increase by increasing the amount of plastic pre-straining. Under a given applied load, the rupture time and creep ductility were found to decrease by increasing the percentage of material pre-straining, though the average and minimum creep strain rates were found to be relatively insensitive to material pre-compression. The creep ductility of the $4 \%, 8 \%$ and $12 \%$ PC materials were found to follow the creep ductility against normalised stress (applied stress normalised by the $0.2 \%$ proof stress) trend at $550{ }^{\circ} \mathrm{C}$ estimated in previous work from AR data. Similar CCG behaviour was observed in the 4\% PC and 8\% PC materials and the data followed the trend of the upper bound fit to the long term data on the AR material. 12\% PC data provide a conservative estimate of the long term CCG behaviour in the AR material, in much shorter time scales. Less conservative predictions may be made by performing tests on $4 \%$ and $8 \%$ PC materials. The CCI data from the PC materials fall close to the experimental trend calculated for the $8 \%$ PC material, when the data are correlated with the $C^{*}$ fracture mechanics parameter, and provide a conservative prediction of the CCI behaviour in long term tests on the AR material. 
Tables

Table 1: Tensile properties of the AR, 4\% PC, $8 \%$ PC and $12 \%$ PC materials at room temperature and $550{ }^{\circ} \mathrm{C}$

\begin{tabular}{|c|c|c|c|c|c|c|}
\hline $\begin{array}{l}\text { Material } \\
\text { Condition }\end{array}$ & Temperature & $\begin{array}{c}E \\
(\mathrm{GPa})\end{array}$ & $\begin{array}{c}\sigma_{0.2} \\
(\mathrm{MPa})\end{array}$ & $\begin{array}{c}\sigma_{0.5} \\
(\mathrm{MPa})\end{array}$ & $\begin{array}{c}\text { UTS } \\
(\mathrm{MPa})\end{array}$ & $\begin{array}{l}\mathcal{E}_{f}^{e n g} \\
(\%)\end{array}$ \\
\hline $\mathrm{AR}$ & \multirow{4}{*}{ Room } & 205 & 313 & 336 & 603 & 62.99 \\
\hline $4 \% \mathrm{PC}$ & & 197 & 251 & 339 & 616 & 64.19 \\
\hline $8 \% \mathrm{PC}$ & & 205 & 256 & 347 & 604 & 60.38 \\
\hline $12 \% \mathrm{PC}$ & & 199 & 280 & 394 & 622 & 48.36 \\
\hline $\mathrm{AR}$ & \multirow{4}{*}{$550{ }^{\circ} \mathrm{C}$} & 140 & 177 & 199 & 432 & 46.70 \\
\hline $4 \% \mathrm{PC}$ & & 134 & 237 & 269 & 417 & 40.24 \\
\hline $8 \%$ PC & & 140 & 259 & 296 & 441 & 39.62 \\
\hline $12 \% \mathrm{PC}$ & & 139 & 346 & 374 & 444 & 26.89 \\
\hline
\end{tabular}

Table 2: A summary of the uniaxial creep rupture data on the $4 \%$ PC, $8 \%$ PC and $12 \%$ PC materials

\begin{tabular}{|c|c|c|c|c|c|c|c|}
\hline Test ID & $\begin{array}{c}\text { Material } \\
\text { Condition }\end{array}$ & $\begin{array}{c}\sigma_{\text {nom }} \\
(\mathrm{MPa})\end{array}$ & $\begin{array}{c}\sigma_{\text {true }} \\
(\mathrm{MPa})\end{array}$ & $\begin{array}{c}\dot{\varepsilon} \\
\left(\mathrm{h}^{-1}\right)\end{array}$ & $\begin{array}{c}t_{r} \\
(\mathrm{~h})\end{array}$ & $\begin{array}{c}\varepsilon_{p l} \\
(\%)\end{array}$ & $\begin{array}{c}\varepsilon_{f} \\
\text { Axial } \\
(\%)\end{array}$ \\
\hline 4PC-1 & $4 \%$ PC & 320 & 329 & $4.73 \times 10^{-4}$ & 288 & 3.05 & 31.19 \\
\hline 8PC-1 & $8 \%$ PC & 325 & 327 & $1.43 \times 10^{-4}$ & 266 & 1.11 & 9.89 \\
\hline 8PC-2 & $8 \%$ PC & 350 & 355 & $4.11 \times 10^{-4}$ & 188 & 2.47 & 12.05 \\
\hline 8PC-3 & $8 \%$ PC & 362 & 380 & $1.30 \times 10^{-4}$ & 460 & 4.52 & 9.02 \\
\hline 8PC-4 & $8 \%$ PC & 375 & 390 & $2.40 \times 10^{-3}$ & 38 & 6.10 & 17.40 \\
\hline 8PC-5 & $8 \%$ PC & 375 & 390 & $1.11 \times 10^{-4}$ & 271 & 6.10 & 4.32 \\
\hline 8PC-6 & $8 \%$ PC & 380 & 409 & $7.36 \times 10^{-4}$ & 119 & 7.34 & 11.33 \\
\hline 8PC-7 & $8 \%$ PC & 385 & 419 & $7.38 \times 10^{-4}$ & 79 & 8.68 & 8.25 \\
\hline 8PC-8 & $8 \%$ PC & 400 & 449 & $4.61 \times 10^{-3}$ & 28 & 11.90 & 21.41 \\
\hline 8PC-9 & $8 \%$ PC & 400 & 449 & $2.80 \times 10^{-4}$ & 119 & 11.90 & 7.49 \\
\hline 12PC-1 & $12 \%$ PC & 257 & 257 & $7.13 \times 10^{-6}$ & 815 & 0.00 & 0.84 \\
\hline 12PC-2 & $12 \%$ PC & 270 & 270 & $6.38 \times 10^{-6}$ & 713 & 0.00 & 0.79 \\
\hline 12PC-3 & $12 \%$ PC & 280 & 281 & $8.84 \times 10^{-6}$ & 740 & 0.00 & 1.01 \\
\hline 12PC-4 & $12 \%$ PC & 300 & 301 & $1.87 \times 10^{-5}$ & 285 & 0.04 & 0.70 \\
\hline 12PC-5 & $12 \%$ PC & 320 & 321 & $3.76 \times 10^{-5}$ & 293 & 0.08 & 1.49 \\
\hline 12PC-6 & $12 \%$ PC & 340 & 341 & $8.76 \times 10^{-5}$ & 150 & 0.18 & 1.92 \\
\hline
\end{tabular}


Table 3: The rupture time, average and minimum creep strain rate power law constants for the AR, $8 \%$ PC and $12 \%$ PC materials

\begin{tabular}{|c|c|c|c|c|c|c|}
\hline Material Condition & $\begin{array}{c}A \\
\left(\mathrm{MPa}^{-n} \mathrm{~h}^{-1}\right)\end{array}$ & $n$ & $\begin{array}{c}A_{A} \\
\left(\mathrm{MPa}^{-n} \mathrm{~h}^{-1}\right)\end{array}$ & $n_{A}$ & $\begin{array}{c}B_{r} \\
\left(\mathrm{MPa}^{v} \mathrm{~h}\right)\end{array}$ & $v_{r}$ \\
\hline AR & $1.60 \times 10^{-34}$ & 11.8 & $5.05 \times 10^{-28}$ & 9.3 & $1.28 \times 10^{26}$ & 9.2 \\
\hline $8 \% \mathrm{PC}$ & $6.42 \times 10^{-38}$ & 13.2 & $4.12 \times 10^{-38}$ & 13.3 & $9.96 \times 10^{24}$ & 8.9 \\
\hline $12 \% \mathrm{PC}$ & $4.11 \times 10^{-29}$ & 9.6 & $7.05 \times 10^{-28}$ & 9.1 & $8.96 \times 10^{17}$ & 6.2 \\
\hline
\end{tabular}

Table 4: A summary of C(T) specimen dimensions, loading conditions and CCG test results

\begin{tabular}{|c|c|c|c|c|c|c|c|c|c|c|}
\hline $\begin{array}{c}\text { Test } \\
\text { ID }\end{array}$ & PC Level & $\begin{array}{c}\text { Header } \\
\text { ID }\end{array}$ & $\begin{array}{c}W \\
(\mathrm{~mm})\end{array}$ & $\begin{array}{c}B \\
(\mathrm{~mm})\end{array}$ & $\begin{array}{c}B_{n} \\
(\mathrm{~mm})\end{array}$ & $a_{0} / W$ & $\begin{array}{c}K\left(a_{0}\right) \\
(\mathrm{MPa} \sqrt{\mathrm{m}})\end{array}$ & $\sigma_{\text {ref }} / \sigma_{0.2}$ & $\begin{array}{c}t_{f} \\
(\mathrm{~h})\end{array}$ & $\begin{array}{c}\Delta a \\
(\mathrm{~mm})\end{array}$ \\
\hline 4PC-A1 & $4 \%$ & $\mathrm{~A}$ & 50 & 25 & 17.5 & 0.5 & 19.8 & 0.36 & 10155 & 4.3 \\
\hline 4PC-A2 & $4 \%$ & $\mathrm{~A}$ & 50 & 25 & 17.5 & 0.5 & 28.0 & 0.51 & 4965 & 1.6 \\
\hline 4PC-B3 & $4 \%$ & $\mathrm{~B}$ & 50 & 25 & 20.0 & 0.5 & 26.7 & 0.46 & 525 & 6.9 \\
\hline 8PC-A5 & $8 \%$ & $\mathrm{~A}$ & 50 & 25 & 17.7 & 0.5 & 21.8 & 0.36 & 502 & 8.3 \\
\hline 8PC-A6 & $8 \%$ & $\mathrm{~A}$ & 50 & 25 & 13.5 & 0.35 & 25.5 & 0.38 & 829 & 8.4 \\
\hline 8PC-A7 & $8 \%$ & $\mathrm{~A}$ & 50 & 25 & 17.5 & 0.35 & 25.5 & 0.33 & 1144 & 7.2 \\
\hline 8PC-A8 & $8 \%$ & $\mathrm{~A}$ & 50 & 25 & 17.5 & 0.35 & 25.5 & 0.33 & 1107 & 9.1 \\
\hline 8PC-A9 & $8 \%$ & $\mathrm{~A}$ & 50 & 25 & 17.5 & 0.35 & 25.5 & 0.33 & 973 & 9.5 \\
\hline 8PC-A10 & $8 \%$ & $\mathrm{~A}$ & 50 & 25 & 17.5 & 0.35 & 25.5 & 0.33 & 860 & 9.6 \\
\hline 12PC-A1 & $12 \%$ & $\mathrm{~A}$ & 50 & 25 & 17.5 & 0.5 & 21.8 & 0.27 & 1061 & 5.5 \\
\hline 12PC-A2 & $12 \%$ & $\mathrm{~A}$ & 50 & 25 & 17.5 & 0.5 & 21.0 & 0.26 & 509 & 6.0 \\
\hline
\end{tabular}

Table 5: CCG power law constants for the as-received and pre-compressed materials

\begin{tabular}{|c|c|c|c|}
\hline Material & $\phi$ & $D$ & UB/LB factor \\
\hline AR (Short term) & 0.89 & 11 & 2.17 \\
\hline AR (Long term) & 0.73 & 9 & 1.83 \\
\hline $4 \%$ PC* & 0.97 & 320 & - \\
\hline $8 \%$ PC & 0.75 & 23 & 3.00 \\
\hline $12 \%$ PC & 0.75 & 65 & - \\
\hline
\end{tabular}

$*$ The best fit made to the linear region 


\section{Figures}
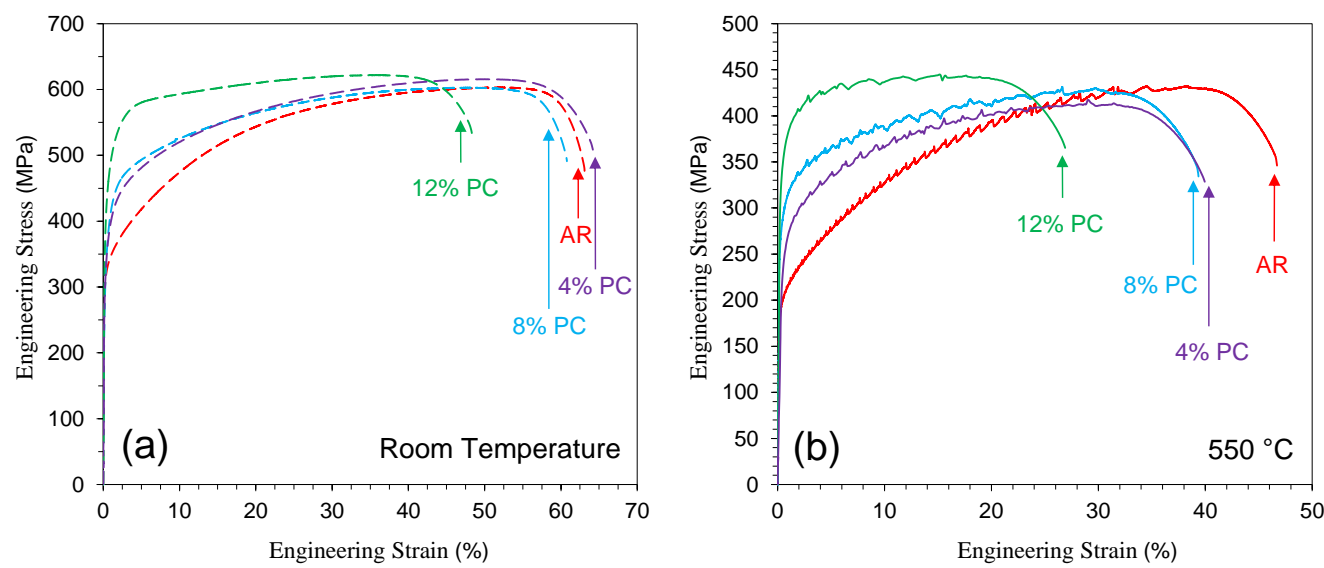

Figure 1: Tensile curves for the AR, 4\% PC, 8\% PC and $12 \%$ PC materials at (a) room temperature (b) $550{ }^{\circ} \mathrm{C}$

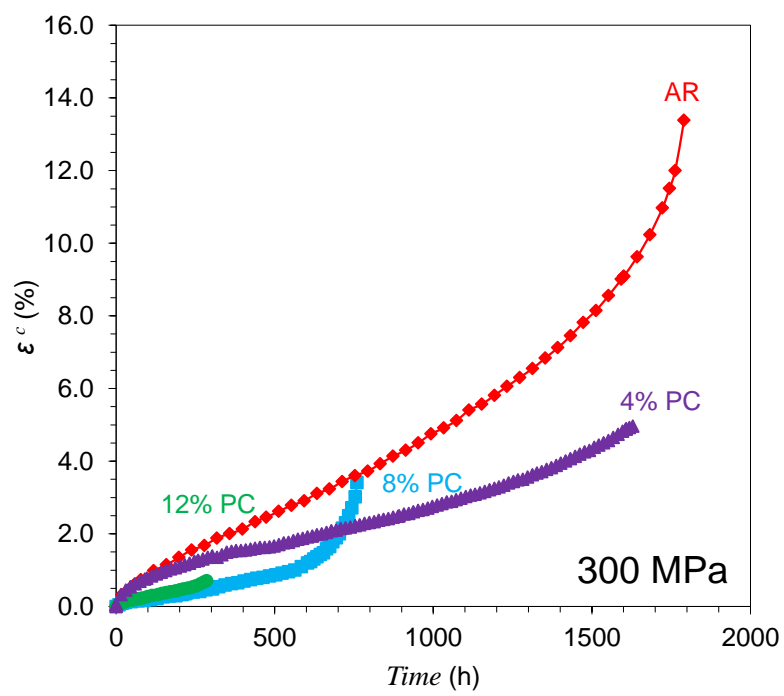

Figure 2: Comparison of the creep curves for the AR, 4\% PC, 8\% PC and 12\% PC materials tested at $300 \mathrm{MPa}$ 


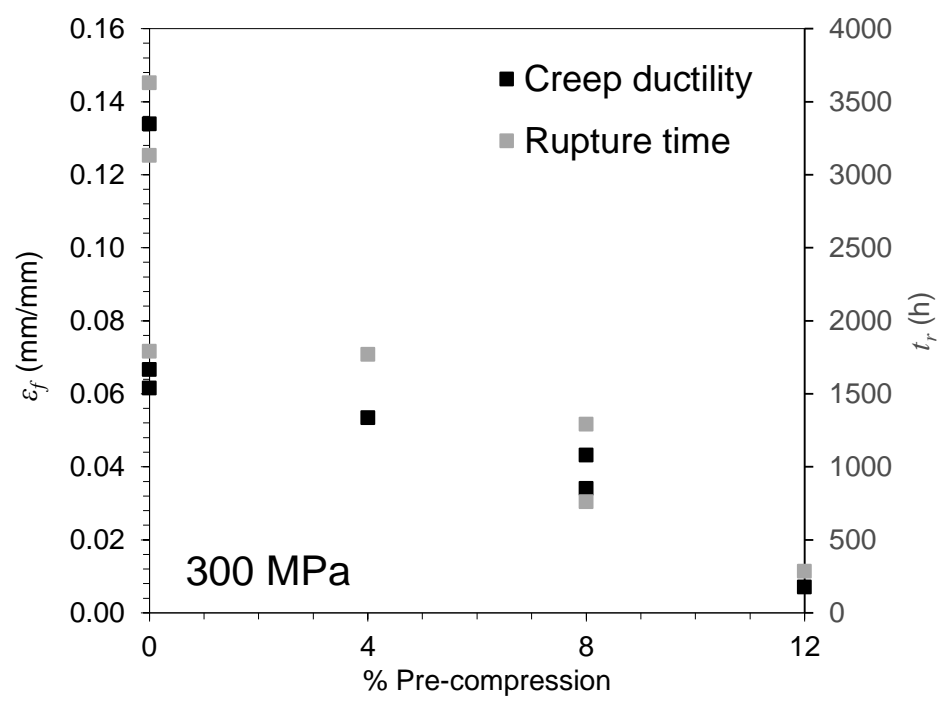

Figure 3: The effect of percentage pre-compression on the creep ductility and rupture time variation of $316 \mathrm{H}$ steel at $300 \mathrm{MPa}$ and $550{ }^{\circ} \mathrm{C}$

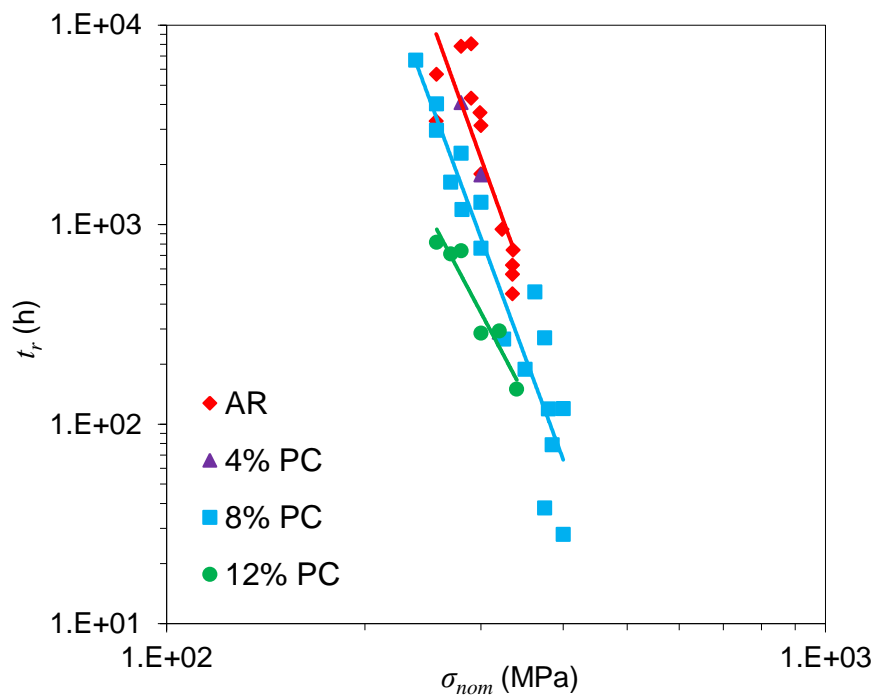

Figure 4: Comparison of the rupture time trends for the AR, 4\% PC, 8\% PC and $12 \%$ PC materials 

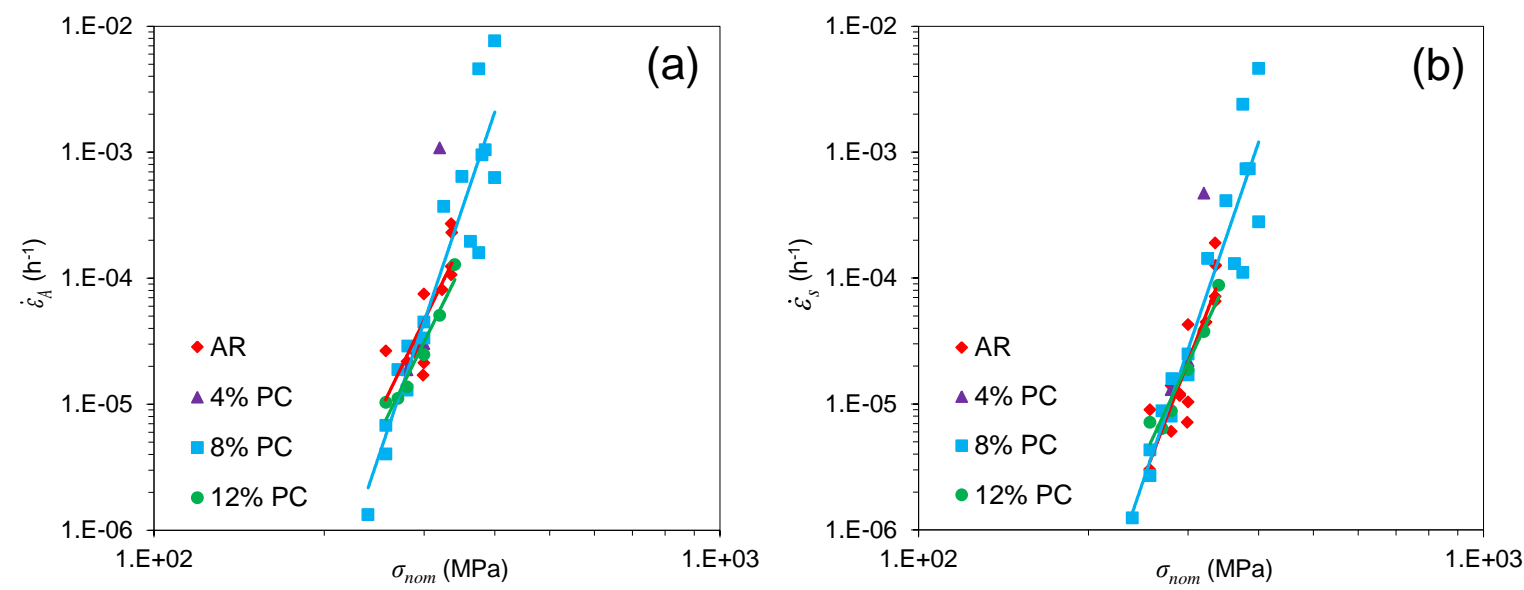

Figure 5: Comparison of the (a) average creep strain rate and (b) minimum creep strain rate trends for the AR, $4 \%$ PC, $8 \%$ PC and $12 \%$ PC materials

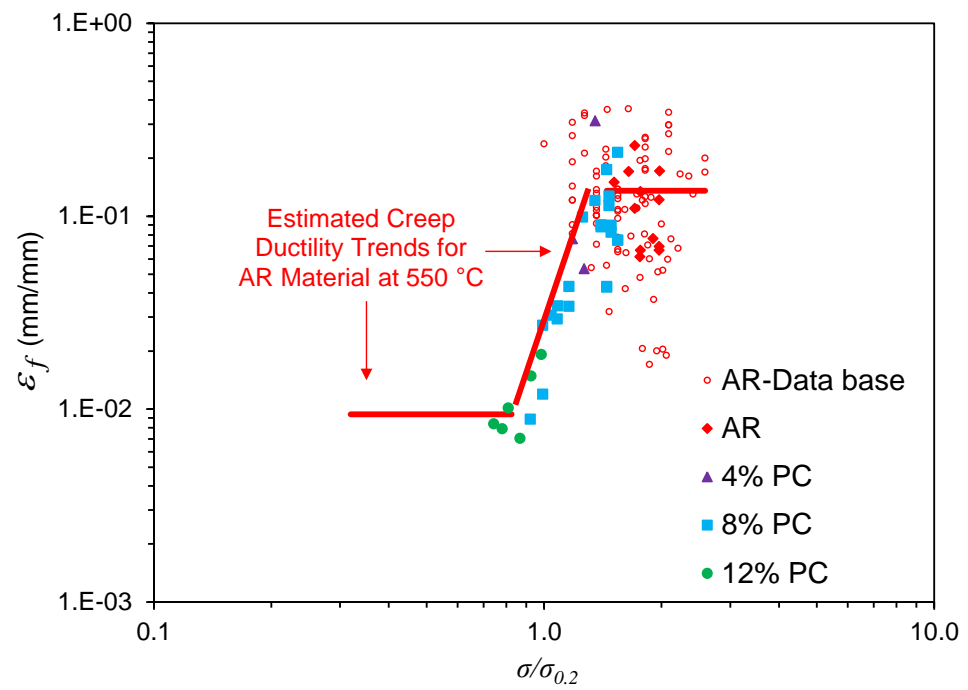

Figure 6: Comparison of the axial creep ductility data points for the AR and PC materials with the estimated trends for the AR material 

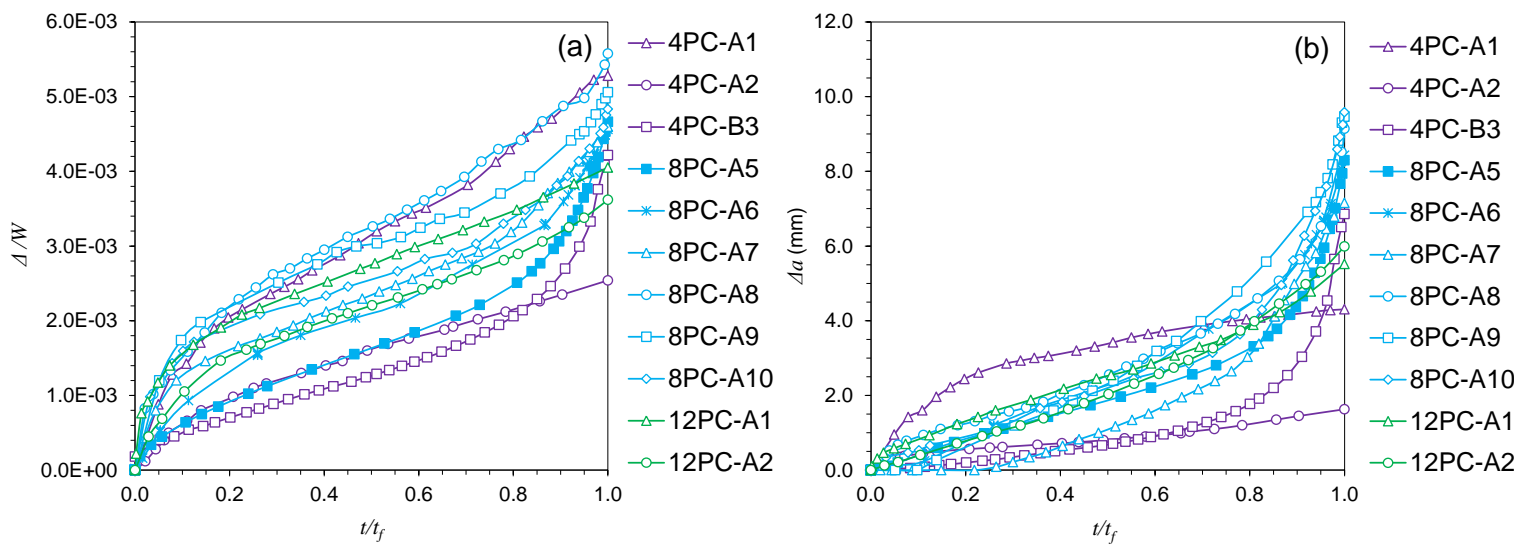

Figure 7: The variation of (a) load line displacement normalised by the specimen width and (b) the creep crack extension, against time normalised by the test duration for the CCG tests performed on PC specimens

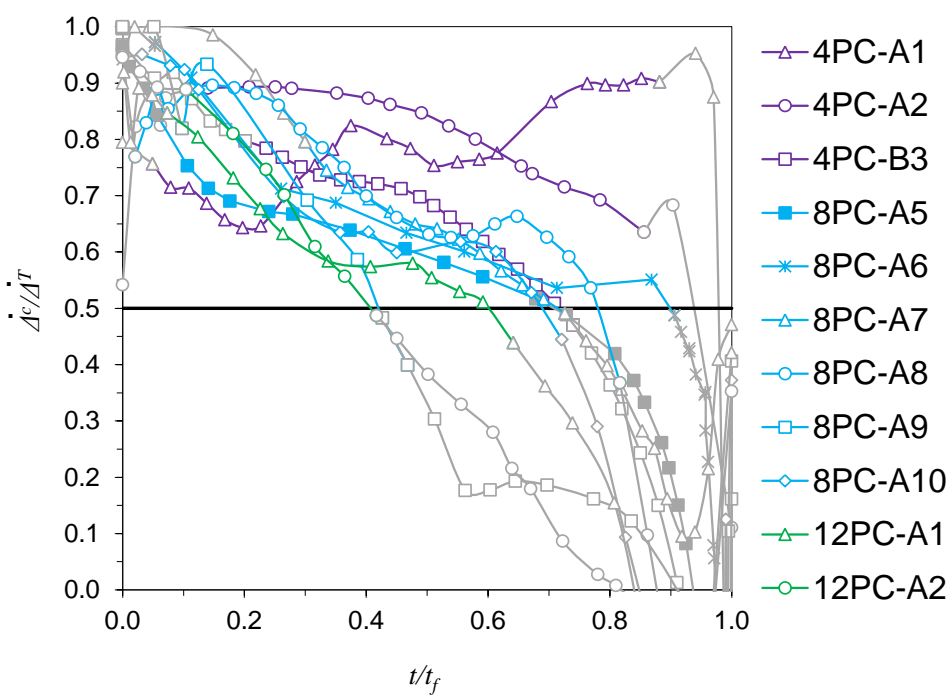

Figure 8: $C^{*}$ validity criteria for the CCG tests performed on PC specimens 


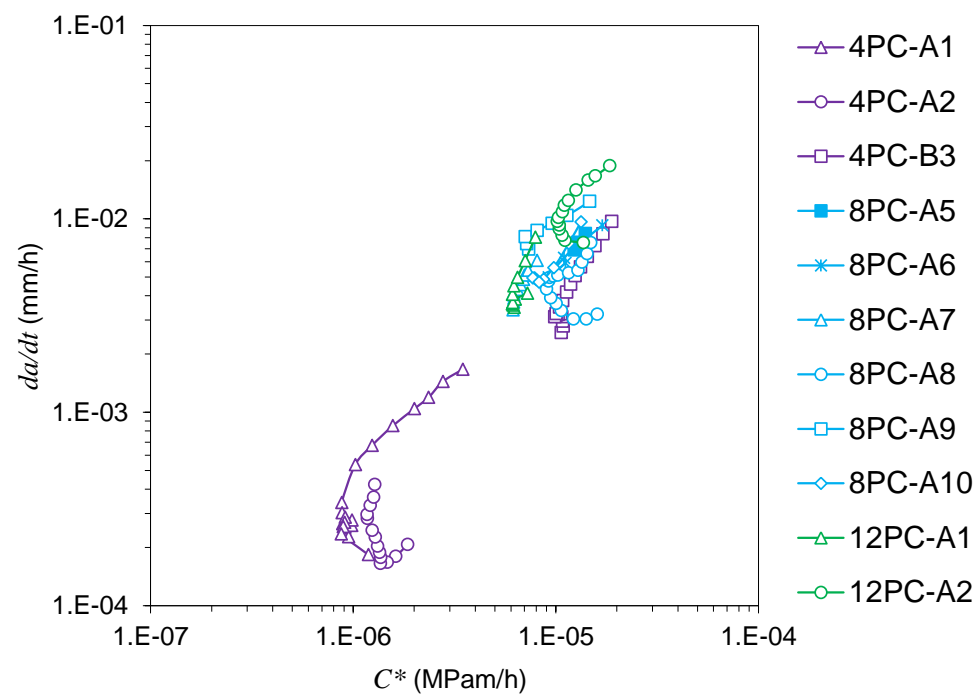

Figure 9: Comparison of the $d a / d t$ vs. $C^{*}$ trends for the CCG tests performed on the PC specimens

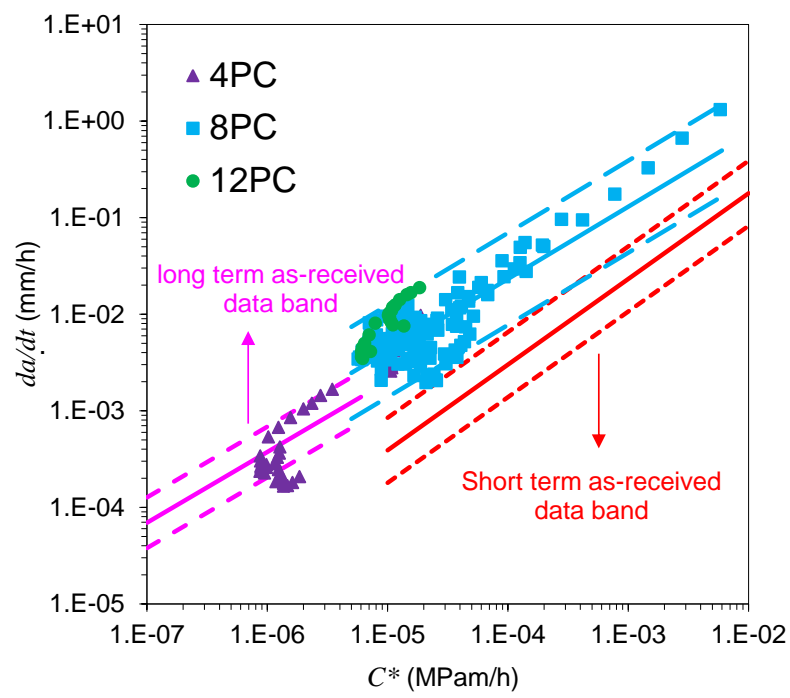

Figure 10: Comparison of the CCG trends for the as-received and pre-compressed materials 


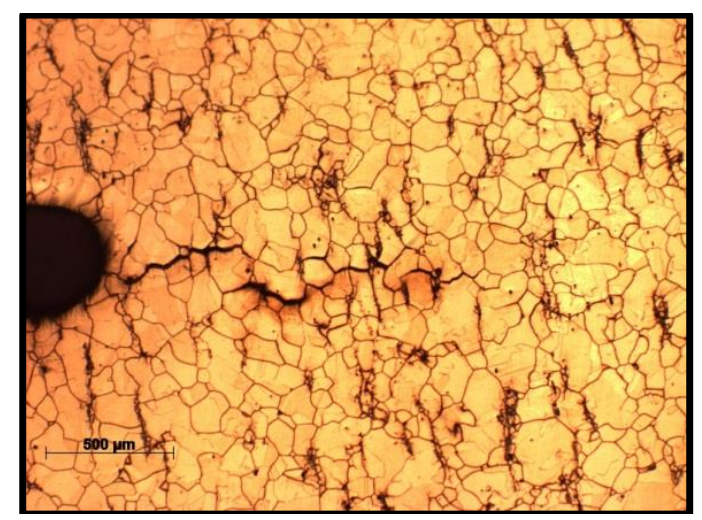

Figure 11: Creep cracking mode in a 4\% PC specimen (4PC-A2)
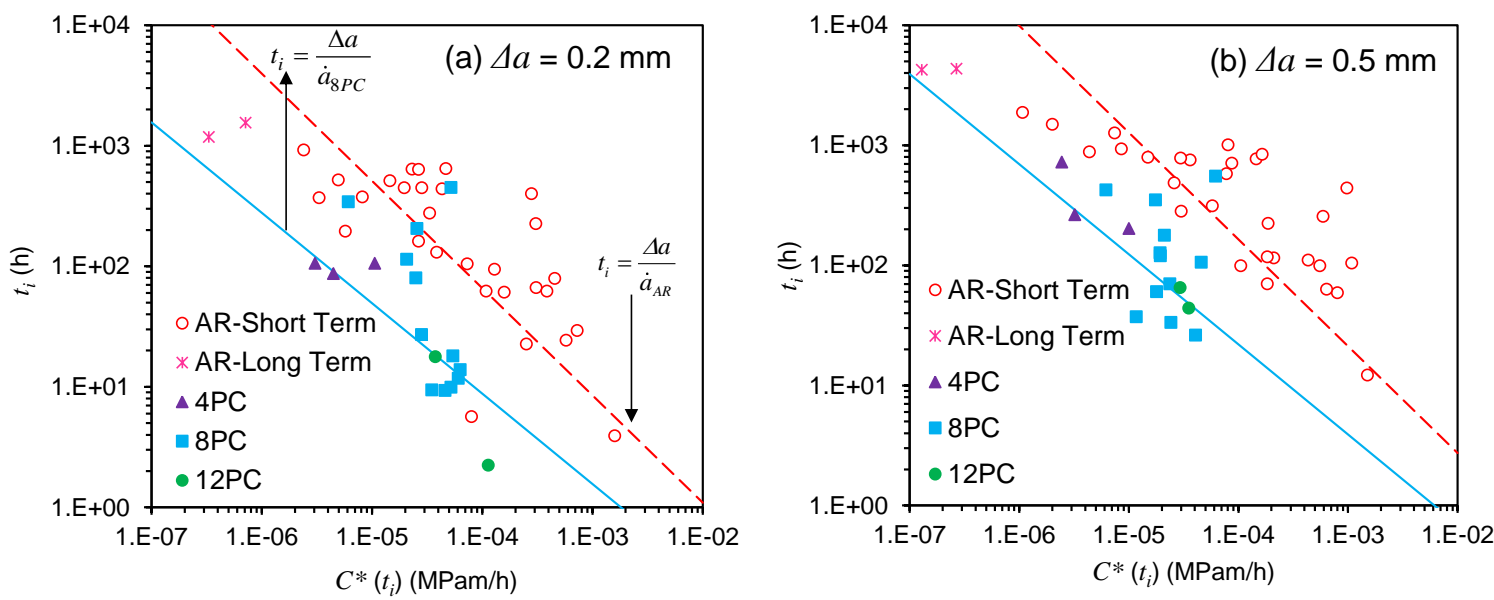

Figure 12: Creep crack initiation trends corresponding to (a) $0.2 \mathrm{~mm}$ and (b) $0.5 \mathrm{~mm}$ crack extension, for the PC and AR materials 


\section{References}

[1] Acar MO, Gungor S, Bouchard PJ, Fitzpatrick ME. Effect of Prior Cold Work on the Mechanical Properties of Weldments Experimental and Applied Mechanics, Volume 6.17:817-26.

[2] Auzoux Q, Allais L, Caës C, Monnet I, Gourgues AF, Pineau A. Effect of pre-strain on creep of three AISI 316 austenitic stainless steels in relation to reheat cracking of weld-affected zones. Journal of Nuclear Materials. 2010;400:127-37.

[3] Li DF, O'Dowd NP, Davies CM, Nikbin KM. A review of the effect of prior inelastic deformation on high temperature mechanical response of engineering alloys. The International journal of pressure vessels and piping. 2010;87:531-42.

[4] Mehmanparast A, Davies CM, Dean DW, Nikbin K. Material pre-conditioning effects on the creep behaviour of 316H stainless steel. International journal of pressure vessels and piping. 2013;108-109:88-93.

[5] Mehmanparast A, Davies CM, Dean DW, Nikbin KM. The Influence of Pre-Compression on the Creep Deformation and Failure Behaviour of Type 316H Stainless Steel. Engineering Fracture Mechanics. 2013;110:52-67.

[6] Parker JD, Wilshire B. The effects of prestrain on the creep and fracture behavior of polycrystalline copper. Materials Science and Engineering. 1980;43:271-80.

[7] Dyson BF, Rodgers MJ. Prestrain, Cavitation, and Creep Ductility. Metal Science. 1974;8:261-6.

[8] Kikuchi S, Ilschner B. Effects of a small prestrain at high temperatures on the creep behaviour of AISI 304 stainless steel. Scripta Metallurgica. 1986;20:159-62.

[9] Willis M, McDonaugh-Smith A, Hales R. Prestrain effects on creep ductility of a 316 stainless steel light forging. International journal of pressure vessels and piping. 1999;76:355-9.

[10] Davies PW, Wilshire B, Richards JD. Influence of cold work on creep and fracture behaviour of a dilute nickel alloy. J Inst Met,. 1962;90:431-3.

[11] Vijayanand VD, Nandagopal M, Parameswaran P, Laha K, Mathew MD. Effect of Prior Cold Work on Creep Rupture and Tensile Properties of 14Cr-15Ni-Ti Stainless Steel. Procedia Engineering. 2013;55:78-81.

[12] Mahalingam S. Effect of pre-strain on grain size distributions in $316 \mathrm{H}$ austenitic stainless steel. Journal of materials science. 2012;47:960-8.

[13] Mehmanparast A, Davies CM, Ardakani M, Nikbin KM. A Microstructural Study of Compressive Plastic Pre-Strain Effects on Creep Damage Behaviour of Type 316H Stainless Steel. ASME-PVP 17-21 July Baltimore-US: proceedings of the International Conference on Pressure Vessels and Piping; 2011.

[14] Davies CM, Dean DW, Nikbin KM. The Influence of Compressive Plastic Pre-Strain on the Creep Deformation and Damage Behaviour of $316 \mathrm{H}$ Stainless Steel. International Conference on Engineering Structural Integrity Assessment 19th-20th May. Manchester, UK: EMAS Publishing; 2009.

[15] Davies CM, Dean DW, Mehmanparast A, Nikbin KM. Compressive Pre-Strain Effects on the Creep and Crack Growth Behaviour of 316H Stainless Steel. ASME-PVP 18-23 July Seattle-US: proceedings of the International Conference on Pressure Vessels and Piping; 2010.

[16] Norton FH. The Creep of Steel at High Temperatures: McGraw-Hill, New York, NY, USA; 1929.

[17] Webster GA, Ainsworth RA. High Temperature Component Life Assessment. 1st ed. London: Chapman and Hall; 1994.

[18] Davies CM, Kourmpetis M, O'Dowd NP, Nikbin KM. Experimental Evaluation of the $J$ or $C^{*}$ Parameter for a Range of Cracked Geometries. Journal of ASTM International. 2006;3:1-20.

[19] ASTM. E1457-07: Measurement of Creep Crack Growth Rates in Metals. Annual Book of ASTM Standards: ASTM International; 2007. p. 1012-35.

[20] EDF Energy. R5: Assessment Procedure for the High Temperature Response of Structures. 2012.

[21] Dean DW, Gladwin DN. Creep Crack Growth Behaviour of Type 316H Steels and Proposed Modifications to Standard Testing and Analysis Methods. International Journal of Pressure Vessels and Piping. 2007;84:378-95. 
[22] Anderson TL. Fracture Mechanics: Fundamentals and Application. Boston: CRC Press; 1991.

[23] Mehmanparast A, Davies CM, Webster GA, Nikbin KM. Creep Crack Growth Rate Predictions in 316H Steel using Stress Dependent Creep Ductility. Materials at High Temperatures. 2014;31:84-94.

[24] Ainsworth RA. The Assessment of Defects in Structures of Strain Hardening Material. Engineering Fracture Mechanic. 1984;19:633-42.

[25] Davies CM, Mueller F, Nikbin KM, O'Dowd NP, Webster GA. Analysis of Creep Crack Initiation and Growth in Different Geometries for $316 \mathrm{H}$ and Carbon Manganese Steels. Journal of ASTM International. 2006;3:1-20.

[26] Nikbin KM, Smith, D.J., Webster, G.A. Prediction of Creep Crack Growth from Uniaxial Creep Data. Proceedings of the Royal Society. 1984;A 396:183-97.

[27] Wilshire B, Battenbough AJ. Creep and creep fracture of polycrystalline copper. Materials science \& engineering A, Structural materials: properties, microstructure and processing. 2007;443:156-66. 